\title{
Topographic features of sheep skin and coat structure
}

\author{
O.K. Gogaev ${ }^{1,2 *}$, A.R. Demurova ${ }^{1}$
}

${ }^{1}$ Gorsky State Agrarian University, 362040, RNO-Alania, Vladikavkaz, Kirov Street, 37; ${ }^{2}$ North Caucasus Research Institute of Mining and Foothill Agriculture - a branch of the Federal State Budgetary Institution of Science of the Federal Scientific Center "Vladikavkaz Scientific Center of the Russian Academy of Sciences", 363110, RNO-Alania, Prigorodny district, Mikhailovskoye village, Williams Street, 1.

*Corresponding author email: texmen2@mail.ru

Journal of Livestock Science (ISSN online 2277-6214) 12: 141-146

Received on 18/2/21, Accepted on 8/4/2021, Published on 21/4/21

doi. 10.33259/JLivestSci.2021.141-146

\begin{abstract}
In the case of insufficient attention of the breeder to sheep selection according to wool uniformity, a fairly large group of animals with wool unequal in length and fineness within the staple and along the fleece appears in the herd. The breeder's excessive enthusiasm for wool uniformity in the fleece leads to the weakening of the sheep's body composition and decreased vigor. The Republic of North Ossetia-Alania, research was carried out in 2019-2020. The geographic location of the farm: Northern latitude: 43.175598. Eastern longitude: 44.295621 and 412 meters above sea level. For the experiment, 10 fine-wooled mongrel winter lambing double-toothed gimmers were selected according to the principle of pairs-analogs. In the spring before shearing, samples of wool and skin on the upper part of the neck, shoulder, back, rump, thigh, flank, shoulder blade, and belly were taken from 14-month-old test double-toothed gimmers. Based on the studies carried out, one can make the following conclusions: - despite the wool homogeneity in the fleece, within different topographic areas, sheep skin has an unequal thickness and structure, which largely determines the coat quality; - the thickest skin in the test sheep was found along the back line. From the back to the flanks, the thickness of the skin decreases. The thinnest skin was on the belly; - on thicker skin, a longer and thicker coat grows, on thinner skin, a shorter and thinner coat grows; - with a change in the wool fiber density, the epidermis thickness changes. The thicker the coat, the thinner the epidermis, the thicker the epidermis, the more scanty the coat; - within different skin topographic areas, the PFs (primary follicles) and SFs (secondary follicles) depth and the ratio of these values are different, which affects the evenness of wool equal in length and untrue wool. The rump, neck, shoulder, and thigh had the maximal PF/SF depth ratio. The same topographic areas were characterized by lesser wool uniformity in length and fineness.
\end{abstract}

Keywords: hair follicles; wool clip; fleece thickness; epidermis; papillary dermis; reticular layer 


\section{Introduction}

The study of skin and coat formation regularity is an important component of the perception of the pattern in sheep individual development. The knowledge of the skin and coat structure allows developing a theoretically grounded strategy for increasing wool productivity while improving the commercial properties of wool raw materials. More attention is paid to the study of leather in sheep breeding compared to other animal husbandry branches. The skin and coat formation features in the embryonic and postembryonic periods, as well as the influence of various factors on the skin and coat formation and the use of the laws of these processes in breeding work, have been well studied (Beerman et al., 1995; Bazarov et al., 2016; Gogaev et al., 2016;Trukhachev et al., 2018; Duckett et al.,2000; Lamanov et al.,2020). Much attention to the skin structure and formation in sheep is explained by the fact that the quantity and quality of wool produced by them are closely dependent on the skin structure and function.

The study of topographic features of the skin and coat structure has significant theoretical and practical interest for the selection and stock breeding of sheep with a unimodal coat (Kesaev et al., 2013; Gogaev et al., 2017; Gogaev et al., 2019; Gogaev et al., 2019).

In the case of insufficient attention of the breeder to sheep selection according to wool uniformity, a fairly large group of animals with wool unequal in length and fineness within the staple and along the fleece appears in the herd. The breeder's excessive enthusiasm for wool uniformity in the fleece leads to the weakening of the sheep's body composition and decreased vigor.

Therefore, to determine the optimal wool uniformity, it is necessary to study in detail the topographic features in the skin structure and wool quality of sheep of different breeds and areas of productivity (Gogaev et al., 2018; Gogaev et al., 2018; Gogaev et al., 2019; Gogaev et al., 2019; Gogaev et al., 2020).

\section{Material and methods}

To study the topographic features in the skin structure and the sheep wool quality in the Peasant Farm "Dzhigkaev Valery Sergeevich" of the Ardon District of the Republic of North Ossetia-Alania, research was carried out in 2019-2020. The geographic location of the farm: Northern latitude: 43.175598. Eastern longitude: 44.295621 and 412 meters above sea level. For the experiment, 10 fine-wooled mongrel winter lambing double-toothed gimmers were selected according to the principle of pairs-analogs. In the spring before shearing, samples of wool and skin on the upper part of the neck, shoulder, back, rump, thigh, flank, shoulder blade, and belly were taken from 14-month-old test double-toothed gimmers.

The resulting digital material was processed by the variation statistics method with the calculation of the appropriate criteria.

\section{Results and discussion}

The authors' data on the change in the sheep skin thickness depending on the topographic areas are shown in Table 1.The data in Table 1 demonstrate that the minimal epidermis thickness was on the sacrum, the largest one - on the belly. Within other topographic areas, the epidermis thickness was approximately the same and was expressed in average values. According to the papillary dermis thickness, various topographic areas can be arranged in the following descending order: rump, shoulder, neck, back, thigh, side, shoulder blade, and belly. Within the reticular layer, the thickness topographic areas are arranged in the same order. Thus, the maximal skin thickness in the test sheep was on the rump, shoulder, neck, and back, i.e. on the chine line, the minimal one - on the belly. The rest of the topographic areas (thigh, flank, and shoulder blade) were in the middle position. When the back skin thickness is taken as 100 percent, then in the remaining topographic areas it will be the neck - 119.1; shoulder - 120.3; back - 107.3; rump - 124.3; thigh - 101.8; shoulder blade - 97.1; belly -88.8 percent.

From the data in Table 2, the ratio of the papillary dermis thickness to the reticular layer one showing the relative skin strength can be calculated for each topographic area. These characteristics will be as follows: neck - 1.86; shoulder -1.87 ; back -1.73 ; rump -1.87 ; thigh -1.77 ; flank -1.77 ; shoulder blade -1.81 ; belly -1.93 . Comparing the given data with skin thickness characteristics within different topographic areas, it can be seen that the belly had the thinnest skin. At the same time, the same area had the maximal ratio of the papillary dermis thickness to the reticular layer one. Thus, the value of the ratio of the papillary dermis thickness to the reticular layer one, although it is an indirect characteristic of the sheepskin strength, can be used when comparing different sheep in the same topographic areas with known care. Notably, the relative thickness of the papillary dermis and reticular layers in different topographic areas was almost the same. Nevertheless, the relative papillary dermis thickness was lower on the back and thigh. A thicker reticular layer was observed within the same areas (Table 2).

The maximal relative epidermis thickness was on the belly, and the minimal one was on the rump, shoulder, and neck. The rest of the areas occupied an intermediate position. Studies of skin preparations also showed that in different topographic areas, the collagen fiber bundle diameter was not the same within the reticular layer: it was maximal on the neck and minimal on the belly. Quite high indicators of the collagen fiber bundle diameter were noted in the shoulder, back, and rump. On the thigh, flank, and shoulder blade, the collagen fiber bundle diameter was average (Table 3). 
Table 1 Thickness of skin and its layers in the test double-toothed gimmers within different topographic areas $(\mu \mathrm{m})$

\begin{tabular}{|l|l|l|l|l|}
\hline Topographic areas & Epidermis & Papillary dermis & Reticular layer & Total skin thickness \\
\hline Neck & $14.1 \pm 0.585$ & $1522.0 \pm 43.585$ & $818.2 \pm 15.420$ & $2354.3 \pm 60.436$ \\
\hline Shoulder & $13.6 \pm 0.660$ & $1542.0 \pm 48.734$ & $823.2 \pm 15.800$ & $2378.4 \pm 64.864$ \\
\hline Back & $15.2 \pm 0.603$ & $1334.3 \pm 17.991$ & $772.0 \pm 14.279$ & $2121.3 \pm 33.112$ \\
\hline Rump & $12.8 \pm 0.498$ & $1593.0 \pm 49.747$ & $854.0 \pm 16.809$ & $2459.6 \pm 67.058$ \\
\hline Thigh & $14.8 \pm 0.746$ & $1274.4 \pm 12.381$ & $721.4 \pm 6.695$ & $2010.6 \pm 17.681$ \\
\hline Flank & $14.0 \pm 0.811$ & $1253.2 \pm 12.732$ & $708.3 \pm 6.368$ & $1976.0 \pm 20.022$ \\
\hline Shoulder blade & $14.5 \pm 0.709$ & $1227.9 \pm 12.261$ & $675.7 \pm 6.208$ & $1918.1 \pm 19.200$ \\
\hline Belly & $17.6 \pm 0.959$ & $1141.1 \pm 14.295$ & $596.8 \pm 6.701$ & $1756.0 \pm 21.742$ \\
\hline
\end{tabular}

Table 2 - Relative skin layer thickness within different topographic areas, \%

\begin{tabular}{|l|l|l|l|l|}
\hline $\begin{array}{l}\text { Topographic } \\
\text { areas }\end{array}$ & $\begin{array}{l}\text { Total skin } \\
\text { thickness }\end{array}$ & Epidermis & $\begin{array}{l}\text { Papillary } \\
\text { dermis }\end{array}$ & $\begin{array}{l}\text { Reticular } \\
\text { layer }\end{array}$ \\
\hline Neck & 100 & 0.60 & 64.65 & 34.75 \\
\hline Shoulder & 100 & 0.57 & 64.83 & 34.60 \\
\hline Back & 100 & 0.71 & 62.90 & 36.39 \\
\hline Rump & 100 & 0.52 & 64.76 & 34.72 \\
\hline Thigh & 100 & 0.74 & 63.38 & 35.88 \\
\hline Flank & 100 & 0.72 & 63.43 & 35.85 \\
\hline Shoulder blade & 100 & 0.76 & 64.01 & 35.23 \\
\hline Belly & 100 & 1.01 & 64.99 & 34.00 \\
\hline
\end{tabular}

Table 3. Thickness of collagen fiber bundles in reticular layer of sheep at different topographic areas of skin $(\mu \mathrm{m})$

\begin{tabular}{|l|l|l|l|l|}
\hline Topographic areas & $\mathrm{n}$ & $\mathrm{M} \pm \mathrm{m}$ & $\sigma$ & $\mathrm{C}_{\mathrm{v}}$ \\
\hline Neck & 10 & $17.1 \pm 0.831$ & 2.63 & 15.37 \\
\hline Shoulder & 10 & $16.2 \pm 0.636$ & 2.01 & 12.43 \\
\hline Back & 10 & $15.1 \pm 0.535$ & 1.69 & 11.20 \\
\hline Rump & 10 & $14.5 \pm 0.475$ & 1.50 & 10.37 \\
\hline Thigh & 10 & $13.3 \pm 0.221$ & 0.70 & 5.26 \\
\hline Flank & 10 & $13.3 \pm 0.235$ & 0.74 & 5.59 \\
\hline Shoulder blade & 10 & $12.3 \pm 0.160$ & 0.51 & 4.13 \\
\hline Belly & 10 & $10.9 \pm 0.192$ & 0.61 & 5.58 \\
\hline
\end{tabular}

Table 4 - Sebaceous gland sizes in sheep within various skin topographic areas $(\mu \mathrm{m})$

\begin{tabular}{|l|l|l|l|l|l|}
\hline Topographic areas & $\mathrm{n}$ & Length & Width \\
\cline { 3 - 6 } & & $\mathrm{M} \pm \mathrm{m}$ & $\mathrm{C}_{\mathrm{v}}$ & $\mathrm{M} \pm \mathrm{m}$ & $\mathrm{C}_{\mathrm{v}}$ \\
\hline Neck & 10 & $200.6 \pm 9.440$ & 14.88 & $86.4 \pm 4.253$ & 15.67 \\
\hline Shoulder & 10 & $173.0 \pm 4.793$ & 8.76 & $75.0 \pm 2.505$ & 10.56 \\
\hline Back & 10 & $177.0 \pm 5.806$ & 10.37 & $69.0 \pm 1.591$ & 7.29 \\
\hline Rump & 10 & $167.0 \pm 4.908$ & 9.29 & $65.0 \pm 1.494$ & 7.27 \\
\hline Thigh & 10 & $188.0 \pm 8.519$ & 14.33 & $77.0 \pm 2.357$ & 9.68 \\
\hline Flank & 10 & $178.0 \pm 9.146$ & 16.25 & $78.0 \pm 2.355$ & 9.55 \\
\hline Shoulder blade & 10 & $192.0 \pm 8.864$ & 14.60 & $78.0 \pm 2.562$ & 10.39 \\
\hline Belly & 10 & $193.0 \pm 8.712$ & 14.27 & $82.0 \pm 2.836$ & 10.94 \\
\hline
\end{tabular}

$\mathrm{M}$ - arithmetic mean; $\mathrm{m}$ - error of average values; $\mathrm{C}_{\mathrm{v}}$ - coefficient of variability

By the collagen fiber bundle diameter, the pattern also changed:

- areas with larger collagen fiber bundles had a more perfect pattern with a large number of loops and branches; - areas with thinner collagen fiber bundles had a weak pattern with a typical parallel arrangement of the bundles.

Given the direct relationship between the strength of the skin and the type of pattern, it can be assumed that the topographic areas with thinner collagen fiber bundles were less durable.

Within different topographic areas, no significant differences in the sweat gland size were found. However, there were significant differences in the depth of sweat glands. On the chine line (neck, shoulder, back, rump), the sweat glands lie approximately at the hair follicle level rarely dropping lower. On the thigh, flank, and shoulder blade, a significant part of the sweat glands lay under the bulbs, but some of them lay at the level of the bulbs, not forming a clearly defined zone. On the belly, the exceeding number of the sweat glands lays below the hair follicles forming a distinct zone as a 
special strip. Within all topographic skin areas, the sebaceous glands were located in the upper third of the papillary dermis. Their sizes within different topographic areas are shown in Table 4.

Table 4 shows that the maximal size of the sebaceous glands was within the areas: neck, belly, and shoulder blade, and the minimal one was on the rump, shoulder, back. It is known that the amount of fat secreted by the sebaceous glands depends not only on the size but also on the amount and intensity of their secretory activity.

It is known that the sebaceous gland number is in direct proportion to the wool fiber density. Consequently, the smaller size of the sebaceous glands on the chine line was compensated by their large number per unit skin area by the greater wool fiber density within certain areas. In the course of the research, a relationship was found between the papillary dermis thickness and the depth of the primary follicles (PFs). The thicker the papillary dermis, the deeper the PFs lie. This is evidenced by the data in Tables 1 and 5. The depth of the follicles, as well as the value showing the ratio of the depth of the PFs to the depth of the secondary follicles (SFs) within various topographic areas, is shown in Table 5.

The data given in Table 5 show that the PF and SF depth within different topographic areas is in direct proportion to the skin thickness. It has been found that the depth of secondary hair follicles within different skin topographic areas is changed according to the depth of the primary hair follicles. The PF and SF depth is changed according to the skin thickness and the wool length within different topographic areas.

Within almost all topographic areas, with an increase in skin thickness, the wool length and the depth of the hair follicles increase. An exception was the thigh, where the hair was longer than within some other topographic areas, and the hair follicle depth was less. The reason for this is that the hair follicles on the thigh lay at an angle to the skin surface, while within other areas, they were located perpendicular to the skin surface. Consequently, the follicle length on the thigh was way more than the depth of their location. However, the values indicating the PF/SF depth ratio are not the same within different topographic areas. Thus, the maximal PF/SF depth ratio was on the rump, neck, shoulder, thigh; the minimal - on the shoulder blade and flank of the test sheep. The rest of the topographic areas according to this characteristic were in the middle position. Different values showing the PF/SF depth ratio within different topographic areas had a corresponding effect on the wool fiber length and fineness uniformity both within the fleece and within the staple. The wool fineness within the topographic areas and the PF/SF fineness ratio are shown in Table 6 .

As already mentioned, such topographic areas as the rump, neck, shoulder, and thigh have the maximal value showing the $\mathrm{PF} / \mathrm{SF}$ depth ratio. Within the same topographic areas, the greatest differences were observed in the fineness of the primary and secondary fibers, i.e. the smallest wool fineness uniformity in the staple (Table 6).

It is interesting to note that the data on wool fineness uniformity is in good agreement with wool length uniformity in the staple and the PF/SF depth ratio. Within topographic areas with lesser wool fineness uniformity, the greatest variation coefficient of the true wool length is also observed (Table 7). The table shows good wool length uniformity on the main body parts. It should be noted that the maximal natural hair length in the test double-toothed gimmers was on the shoulder blade, flank, shoulder, and neck; the minimal was on the belly. In true wool length, in addition to the indicated topographic areas, the back also had high characteristics. The belly and rump had the maximal wool crimp; the thigh had the minimal one. The rest of the topographic areas occupied an intermediate position.

An important characteristic of sheep wool production is wool fiber density. Within different topographic areas, the wool fiber density examined on skin horizontal slices is different. This is evidenced by the data in Table 8 . The maximal follicle number in the hair group (complex) and per skin unit area was on the shoulder, back, and sacrum; the minimal was on the belly and thigh. The rest of the topographic areas according to the specified characteristic were in the middle position. This pattern is found when analyzing the data in Table 9 according to the SF/PF ratio. The lowest $\mathrm{SF} / \mathrm{PF}$ ratio was on the belly and thigh, and the highest was on the shoulder, back, and rump.

It should be noted that in areas of skin with a rare follicle location (belly, thigh), the areas occupied by groups were smaller, the intervals between groups not occupied by hair follicles were large, i.e. groups (complexes) were located in the skin more loosely. Within areas with closely spaced hair follicles, the group areas were larger and the distance between them, free from hair follicles, were as narrow gaps.

Table 5 - Depth of hair follicles in sheep skin depending on topographic areas $(\mu \mathrm{m})$

\begin{tabular}{|c|c|c|c|c|c|}
\hline \multirow{2}{*}{$\begin{array}{l}\text { Topographic } \\
\text { areas }\end{array}$} & \multicolumn{2}{|l|}{ PF depth } & \multicolumn{2}{|l|}{ SF depth } & \multirow{2}{*}{$\begin{array}{l}\text { PF/SF } \\
\text { depth ratio }\end{array}$} \\
\hline & $\mathrm{M} \pm \mathrm{m}$ & $\mathrm{C}_{\mathrm{v}}$ & $\mathrm{M} \pm \mathrm{m}$ & $\mathrm{C}_{\mathrm{v}}$ & \\
\hline Neck & $1535.8 \pm 43.800$ & 9.02 & $814.3 \pm 9.89$ & 5.08 & 1.83 \\
\hline Shoulder & $1557.3 \pm 47.43$ & 9.64 & $840.2 \pm 22.88$ & 11.30 & 1.85 \\
\hline Back & $1346.2 \pm 10.06$ & 2.36 & $761.5 \pm 11.50$ & 4.77 & 1.76 \\
\hline Rump & $1593.8 \pm 9.76$ & 1.99 & $815.9 \pm 12.93$ & 5.00 & 1.95 \\
\hline Thigh & $1291.9 \pm 12.71$ & 3.11 & $685.5 \pm 12.67$ & 5.84 & 1.88 \\
\hline Flank & $1267.8 \pm 13.22$ & 3.29 & $738.0 \pm 7.10$ & 3.51 & 1.71 \\
\hline Shoulder blade & $1245.3 \pm 12.96$ & 3.29 & $750.3 \pm 6.64$ & 3.23 & 1.66 \\
\hline Belly & $1158.5 \pm 14.76$ & 4.02 & $636.5 \pm 13.64$ & 8.04 & 1.82 \\
\hline
\end{tabular}

$M$ - arithmetic mean; $m$ - error of average values; $C_{v}$ - coefficient of variability 
Table 6 - Topographic differences in fiber fineness in the test double-toothed gimmers $(\mu \mathrm{m})$

\begin{tabular}{|l|l|l|l|l|l|l|l|}
\hline \multirow{2}{*}{ Topographic areas } & Primary fibers & \multicolumn{3}{|l|}{ Secondary fibers } & PF/SF \\
\cline { 2 - 8 } & $\mathrm{M} \pm \mathrm{m}$ & $\sigma$ & $\mathrm{C}_{\mathrm{v}}$ & $\mathrm{M} \pm \mathrm{m}$ & 6 & $\mathrm{C}_{\mathrm{v}}$ & ratio \\
\hline Neck & $27.9 \pm 1.72$ & 5.44 & 19.51 & $18.7 \pm 0.32$ & 1.02 & 5.43 & 1.49 \\
\hline Shoulder & $27.3 \pm 1.56$ & 4.94 & 18.10 & $19.7 \pm 0.37$ & 1.17 & 6.26 & 1.46 \\
\hline Back & $26.9 \pm 1.73$ & 3.39 & 12.62 & $18.6 \pm 0.32$ & 1.00 & 5.32 & 1.44 \\
\hline Rump & $27.9 \pm 1.55$ & 4.92 & 17.98 & $18.5 \pm 0.33$ & 1.06 & 5.72 & 1.51 \\
\hline Thigh & $28.0 \pm 1.72$ & 5.43 & 19.39 & $18.6 \pm 0.33$ & 1.05 & 5.66 & 1.50 \\
\hline Flank & $24.0 \pm 1.07$ & 3.39 & 14.10 & $17.7 \pm 0.48$ & 1.52 & 8.57 & 1.36 \\
\hline Shoulder blade & $23.6 \pm 1.05$ & 3.31 & 14.02 & $18.6 \pm 0.24$ & 1.24 & 6.68 & 1.27 \\
\hline Belly & $22.9 \pm 1.15$ & 3.62 & 15.82 & $15.8 \pm 0.39$ & 0.77 & 4.85 & 1.45 \\
\hline
\end{tabular}

$M$ - arithmetic mean; $m$ - error of average values; $C_{v}$ - coefficient of variability; $\sigma$ - mean square deviation

Table 7 - Hair length in the test double-toothed gimmers within different topographic areas $(\mathrm{cm})$

\begin{tabular}{|c|c|c|c|c|c|c|c|}
\hline \multirow{2}{*}{$\begin{array}{l}\text { Topographic } \\
\text { areas }\end{array}$} & \multicolumn{3}{|l|}{ Native } & \multicolumn{3}{|l|}{ True } & \multirow{2}{*}{$\begin{array}{l}\text { True to native } \\
\text { length ratio }\end{array}$} \\
\hline & $\mathrm{M} \pm \mathrm{m}$ & 6 & $\mathrm{C}_{\mathrm{v}}$ & $M \pm m$ & $\sigma$ & $\overline{C_{v}}$ & \\
\hline Neck & $8.0 \pm 0.19$ & 0.60 & 7.50 & $9.2 \pm 0.29$ & 0.66 & 7.17 & 1.15 \\
\hline Shoulder & $8.2 \pm 0.21$ & 0.66 & 7.60 & $9.4 \pm 0.42$ & 1.34 & 14.23 & 1.15 \\
\hline Back & $7.8 \pm 0.13$ & 0.42 & 5.41 & $9.0 \pm 0.13$ & 0.42 & 4.68 & 1.15 \\
\hline Rump & $7.3 \pm 0.13$ & 0.42 & 5.78 & $9.0 \pm 0.40$ & 1.28 & 14.19 & 1.18 \\
\hline Thigh & $8.3 \pm 0.20$ & 0.62 & 7.52 & $9.3 \pm 0.20$ & 1.55 & 16.69 & 1.10 \\
\hline Flank & $8.2 \pm 0.16$ & 0.48 & 5.82 & $9.2 \pm 0.16$ & 0.49 & 5.34 & 1.12 \\
\hline Shoulder blade & $8.3 \pm 0.13$ & 0.42 & 5.07 & $9.3 \pm 0.18$ & 0.56 & 6.06 & 1.12 \\
\hline Belly & $5.3 \pm 0.18$ & 0.55 & 10.42 & $6.9 \pm 0.19$ & 0.51 & 8.80 & 1.30 \\
\hline
\end{tabular}

$M$ - arithmetic mean; $m$ - error of average values; $C_{v}$ - coefficient of variability; $\sigma$ - mean square deviation

Table 8 - Changes in the density of hair follicles depending on the skin topographic areas in the test double-toothed gimmers

\begin{tabular}{|l|l|l|l|l|l|l|}
\hline \multirow{2}{*}{$\begin{array}{l}\text { Topographic } \\
\text { areas }\end{array}$} & \multicolumn{3}{|c|}{ In the group } & \multicolumn{3}{c|}{ Per $\mathrm{mm}^{2}$ skin area } \\
\cline { 2 - 7 } & $\mathrm{M} \pm \mathrm{m}$ & $\sigma$ & $\mathrm{C}_{\mathrm{v}}$ & $\mathrm{M} \pm \mathrm{m}$ & 6 & $\mathrm{C}_{\mathrm{v}}$ \\
\hline Neck & $17.7 \pm 0.44$ & 1.72 & 9.71 & $56.6 \pm 4.121$ & 13.00 & 22.97 \\
\hline Shoulder & $20.8 \pm 1.08$ & 3.41 & 16.38 & $67.1 \pm 4.27$ & 13.49 & 20.10 \\
\hline Back & $19.6 \pm 0.66$ & 2.08 & 10.60 & $56.0 \pm 4.25$ & 13.44 & 24.00 \\
\hline Rump & $21.3 \pm 1.21$ & 3.81 & 18.00 & $61.5 \pm 3.97$ & 12.45 & 20.24 \\
\hline Thigh & $14.7 \pm 0.79$ & 2.49 & 16.91 & $43.3 \pm 3.61$ & 11.40 & 26.33 \\
\hline Flank & $16.7 \pm 0.49$ & 1.54 & 9.20 & $50.5 \pm 3.81$ & 12.04 & 23.94 \\
\hline Shoulder blade & $19.0 \pm 0.75$ & 1.57 & 12.50 & $56.0 \pm 3.83$ & 12.12 & 21.64 \\
\hline Belly & $11.2 \pm 0.50$ & 2.38 & 13.97 & $29.3 \pm 1.89$ & 5.98 & 20.42 \\
\hline
\end{tabular}

$M$ - arithmetic mean; $m$ - error of average values; $C_{v}$ - coefficient of variability; $\sigma$ - mean square deviation

Table 9 - Change in the SF/PF ratio in the skin of test double-toothed gimmers depending on the topographic areas

\begin{tabular}{|l|l|l|l|l|l|l|}
\hline \multirow{2}{*}{$\begin{array}{l}\text { Topographic } \\
\text { areas }\end{array}$} & \multicolumn{3}{|c|}{ In the group } & \multicolumn{2}{c|}{ Per 1 $\mathrm{mm}^{2}$ skin area } \\
\cline { 2 - 7 } & $\mathrm{M} \pm \mathrm{m}$ & $\sigma$ & $\mathrm{C}_{\mathrm{v}}$ & $\mathrm{M} \pm \mathrm{m}$ & $\sigma$ & $\mathrm{C}_{\mathrm{v}}$ \\
\hline Neck & $10.0 \pm 0.30$ & 0.94 & 9.38 & $11.3 \pm 0.35$ & 1.09 & 9.66 \\
\hline Shoulder & $12.6 \pm 0.15$ & 0.46 & 2.89 & $13.9 \pm 0.45$ & 1.43 & 10.27 \\
\hline Back & $13.1 \pm 0.26$ & 0.81 & 6.21 & $12.7 \pm 0.34$ & 1.09 & 8.56 \\
\hline Rump & $12.9 \pm 0.20$ & 0.64 & 4.95 & $14.5 \pm 0.42$ & 1.34 & 9.26 \\
\hline Thigh & $9.5 \pm 0.12$ & 0.37 & 3.89 & $10.9 \pm 0.55$ & 1.72 & 15.82 \\
\hline Flank & $10.8 \pm 0.21$ & 0.77 & 7.00 & $11.1 \pm 0.13$ & 0.41 & 3.71 \\
\hline Shoulder blade & $12.2 \pm 0.17$ & 0.94 & 7.66 & $12.5 \pm 0.31$ & 0.98 & 7.84 \\
\hline Belly & $6.8 \pm 0.30$ & 0.54 & 7.88 & $7.3 \pm 0.23$ & 0.71 & 9.77 \\
\hline
\end{tabular}

$M$ - arithmetic mean; $m$ - error of average values; $C_{v}$ - coefficient of variability; $\sigma$ - mean square deviation

Based on the studies carried out, one can make the following conclusions:

1. Despite the wool homogeneity in the fleece, within different topographic areas, sheep skin has an unequal thickness and structure, which largely determines the coat quality;

2. The thickest skin in the test sheep was found along the back line. From the back to the flanks, the thickness of the skin decreases. The thinnest skin was on the belly.

3. On thicker skin, a longer and thicker coat grows, on thinner skin, a shorter and thinner coat grows.

4. With a change in the wool fiber density, the epidermis thickness changes. The thicker the coat, the thinner the epidermis, the thicker the epidermis, the more scanty the coat.

5. Within different skin topographic areas, the PF and SF depth and the ratio of these values are different, which affects the evenness of wool equal in length and untrue wool. The rump, neck, shoulder, and thigh had the maximal PF/SF depth ratio. The same topographic areas were characterized by lesser wool uniformity in length and fineness. 


\section{References}

1. Bazarov B.M., Rajamuradov Z.T. 2016. Effect of different feeding level karakul sheep in the second half of pregnancy and early lactation on some properties of milk and development of lambs. Eastern European Scientific Journal. №1:9-14.

2. Beerman D.H., Robinson T.F., Hogue D.E. 1995. Impact of composition manipulation on lean lamb production in the United States. J. Anim. Sci. 73: 2493 -2502.

3. Duckett S.K., Snowder G.D., Cockett N.E. 2000. Effect of the callipyge on muscle growth, calpastatin activity, and tenderness of three muscles across the growth curve. J.Anim. Sci. 78:2836 -2841.

4. Gogaev O.K., Kesaev Kh.E., Demurova A.R., Gatsiev U.S. 2016. The Regularities of the Skin and Hair Follicles Formation of Young Sheep of Romanov Breed in the Foothills of the North Caucasus. Proceedings of Gorsky State Agrarian University. 2016. Vol.53. No.1. P.50-57.

5. Gogaev O.K., Kessaev K.E., Kaloev B.S., Kebekov M.E., Tarchokov T.T. 2016. The Skin Formation and Hair Coat of the Romanov Sheep in the Conditions of the Piedmont Zone of the North Caucasus. Asian Journal of Microbiology, Biotechnology and Environmental Sciences. Vol.18. №4: 1027-1036.

6. Gogaev O.K., Kesaev Kh.E., Demurova A.R., Bestaeva R.D., Dzeranova A.V., Kusova V.A. 2017. The Agerelated Changes in the Linear Dimensions of the Bones of the Axial skeleton of Sheep. Veterinary Science of Kuban. 2:15-17.

7. Gogaev O. K., Kessaev Kh. E., Demurova A. R., Gatsiev U. S. 2016. Regularities in the formation of skin and hair follicles of young Romanov sheep in the piedmont zone of the North Caucasus. Proceedings of Gorsky State Agrarian University. 53(1): 50-57.

8. Gogaev O.K. 2018. Postembryonic development of the skin of young Romanov and Tushin ewes under the conditions of the foothill zone in the North Caucasus. Research Journal of Pharmaceutical, Biological and Chemical Sciences. 9(5): 2335-2346.

9. Gogaev O.K., Tukfatulin G.S., Kokoev Kh.P., Vanieva B.B., Margieva F.T. 2018. Histological structure of the skin and wool productivity of sheep of the grozny breed, depending on the folding of the skin. Research Journal of Pharmaceutical, Biological and Chemical Sciences. T. 9. № 5. - C. 1318-1332.

10. Gogaev O.K., Abaev A.A., Demurova A.R. 2019. The patterns of linear skeletal growth of the crossbred sheep. Indo American Journal of Pharmaceutical Sciences. 6(4): 8717-8725.

11. Gogaev O.K., Yuldashbaev Yu.A., Kebekov M.E., Kairov V.R., Kaloev B.S., Demurova A.R. 2019. The features of sheep adaptation to their keeping in mountainous conditions. Indo American Journal of Pharmaceutical Sciences. 6(9):15653-15661.

12. Gogaev . O.K., Demurova A.R., Ikoeva B.K., Tokhtieva E.A. 2020. The effect of different forms of iodine on the blood parameters of sheep. Journal of Livestock Science 11: 40-44. doi. 10.33259/JLivestSci.2020.40-44.

13. Kesaev Kh.E., Gogaev O.K., Bestaeva R.D., Kusova V.A. 2013. The Regularities of Young Sheep' Peripheral Skeleton Muscles Weight Growth. Proceedings of Gorsky State Agrarian University. 50 (4-4): 53-57.

14. Lamanov A., Ivanov Y., Iskhakov R., Zubairova L., Tagirov K., Salikhov A. 2020. Beef quality indicators and their dependence on keeping technology of bull calves of different genotypes. AIMS Agriculture and Food. 5(1):10.

15. Trukhachev V.I., Oleinik S.A., Morozov V.Y., Lesnyak T.S., Sklyarov S.P. 2018. The use of innovative remote monitoring methods for growing Manych merino sheep. Research Journal of Pharmaceutical, Biological and Chemical Sciences. 9(6):1658-1663. 